\title{
Challenges and methods of monitoring the occurrence of unsanctioned voltage in the power grid
}

\author{
Alexander Panfilov ${ }^{1}$, Alexander Vinogradov ${ }^{2}$, Alina Vinogradova ${ }^{2}$, Vadim Bolshev ${ }^{2}$, Zumeira Shakurova ${ }^{3}$, and Elena \\ Zaugolnikova ${ }^{4}$ \\ ${ }^{1}$ Branch of "PJSC Centre-Orelenergo", Orel, Russia \\ ${ }^{2}$ Federal Scientific Agroengineering Center VIM, Moscow, Russia \\ ${ }^{3}$ Kazan State Power Engineering University, Kazan, Russia \\ ${ }^{4}$ NUST MISiS, Moscow, Russia
}

\begin{abstract}
The review of sources dedicated to the issues of monitoring in electric networks made in the article showed that the works of many scientists are aimed at developing methods, technical means, systems for monitoring current and voltage in various operation modes of power grids. The main objectives of monitoring are identified, it is shown that monitoring of parameters in the network operation modes provides observability of the network, which, in turn, allows to make timely decisions about switching in the network, regulating the parameters of the network operation modes. The relevance of monitoring for detecting cases of unauthorized voltage in the $0.4 \mathrm{kV}$ power networks is shown. Similar cases lead to the risk of electric shock to people, increasing the risk of operating electrical networks. Identification of the occurrence of unauthorized voltage in the $0.4 \mathrm{kV}$ network provides ways to prevent its transformation at substations of $10 / 0.4 \mathrm{kV}$ to a voltage of $10 \mathrm{kV}$. Therefore, it is relevant to develop methods for detecting unauthorized voltage in the $0.4 \mathrm{kV}$ electric system. The methodological principles and one of the developed methods for monitoring the occurrence of unauthorized voltage in power transmission lines of $0.4 \mathrm{kV}$ and blocking the reverse transformation on substations $10 / 0.4 \mathrm{kV}$, as well as the device for its implementation, are shown.
\end{abstract}

\section{Introduction}

Monitoring the parameters of the operation modes of rural power grids allows to ensure the implementation of one of the principles of managing the configuration countryside power grids, determined in the [1], specifically, the principle of its observability. The modes of operation of rural power grids are characterized by a constant change in its parameters, which may include current, voltage, power consumption, both active and reactive, and indicators of the quality of electrical energy $[2,3,4]$. In recent studies, the authors point out that large investments are directed in the field of power engineering in the development of the infrastructure of power grids [5,6 ], development of monitoring tools for operating modes of electrical networks, substations [2,3 ] sensors and systems for monitoring and managing the reliability of power supply and power quality $[4,7,8]$, smart electricity meters and its infrastructure, which, in addition to directly accounting, also perform monitoring functions [9-15] .The development of monitoring technologies makes possible to build smart grids that are impossible without ensuring the observability of network operating modes. It is important that monitoring systems allow to reduce the time of interruptions in the power supply of consumers, the time of non-compliance with the quality of electricity supplied to consumers [1]. In particular, given in [1] the example shows how the implementation of monitoring systems can reduce the time for restoring power supply by more than an hour by reducing the time for receiving information about damage in the electrical network and the time for searching for the location of breakage.

It is possible to distinguish the main tasks of monitoring parameters of the operating modes of rural power grids. Monitoring and control of electricity consumption for the purpose of organizing electricity metering is revealed in the works [11-15]. Monitoring and control of consumers' electricity consumption and sections of the power grids in order to identify areas with increased losses is given, for example, in [16]. Monitoring and control of the quality indicators of electricity supplied to consumers in order to regulate and maintain within the standardized limits are shown in [1719]. Monitoring and controlling the power consumption in order to identify the load of individual sections of the network allows to improve the planning of reconstruction and new construction of power grids, as shown in $[1,20]$. In addition, monitoring is performed to identify emergency situations in the network and diagnose, also solving other problems. Monitoring methods are based on the application, firstly, of sensors 
for the parameters of the operating modes of the power grids and consumers. Sensors can have different design and functionality, as well as means of transferring data about the parameters of the grid operation modes at the sensor installation point. Several monitoring methods and the design of various sensor variants are given in [1,4,7,15-18,21].

Measuring devices such as power quality analyzers, multimeters, amperemeters, voltmeters, voltamperemeters, and many others are also often used for monitoring and control. However, given type of monitoring has significant disadvantages. Firstly, these devices do not have, as a rule, data transmission tools, and are not designed for fixed long-term monitoring. Electricity quality analyzers are the most functional of these devices, but it is an expensive equipment and doesn't allow to build a monitoring system.

One of the important monitoring tasks not mentioned above in rural power grids is to improve the safety of maintenance of grids and its operation. In particular, at the present time, due to the insufficiently high reliability of rural grids, which is noted in [22-25], village residents install low-power generators and uninterruptible power supply systems in their farms to reserve power supply to houses in case of failures in the public network. It increases the risk of unsanctioned voltage appearing in the system, since not all consumers strictly follow the rules for connecting generators to internal electrical grids [26], admitting, occasionally, the possibility of supplying voltage from these generators to the general electric network. This leads to possibility of unsanctioned voltage appearing in the electrical network, and this voltage supplied to the low-voltage network can be transformed into a medium-class voltage due to reverse transformation at transformer substations (TS) of 6$20 / 0,4 \mathrm{kV}$. There are cases of deaths due to such a situation, in particular, due to the supply of voltage from the $0.23 \mathrm{kV}$ generator in the Branch of "MRSK Center Yarenergo», an employee died serving the $10 \mathrm{kV}$ line. [27].

In addition, such documents were released as [28], in which it is planned to implement in the power grids of private power generating plants with a capacity of up to $15 \mathrm{~kW}$ connected at a voltage of up to $1000 \mathrm{~V}$, as well as Government Decree No. 328 of March 5, 2021. [29], where the issues of supporting the generation of electricity by renewable energy sources are also considered. These documents regulate the possibility of authorized connection of microgeneration, including from renewable energy sources (RES) to public networks. One of the consequences of this will be a significant complication of the requirements for the safe operation of power grids, as there will be the possibility of unsanctioned supply of voltage from microgenerators to power lines during its maintenance. It will be necessary to ensure a guaranteed shutdown of all generators connected to the network during maintenance and repair of the network, to regulate the operation of microgenerators, their use, issues of interaction of their owners with power supply and power grid organizations, the dispatcher of the electric network to which the microgenerators will be connected. At the same time, these generators will be on the balance of consumer and access to them will be limited. This also requires monitoring the parameters of the operating modes of power grids, as well as the development of methods and technical means to prevent unsanctioned voltage supply and reverse transformation at transformer substations. Thus the purpose of the study is to develop methods for monitoring the parameters of the operating modes of electric networks, allowing to detect unauthorized voltage in the network, as well as to develop methods and technical means to prevent the reverse transformation of this voltage at transformer substations. The novelty of such methods lies in the study and application of patterns of changes in current and voltage at control points of the network, which characterize the appearance of unauthorized voltage in it.

\section{Methods}

The main informative signs for recognizing different situations in electrical networks are the sequences of changes in voltage and current at control points. Based on the analysis of these sequences, various authors have developed many solutions for monitoring the operating modes of electrical networks of different voltages $[30,31]$. Characteristic changes in current and voltage are also used in monitoring systems of electrical networks [4]. Such methods also allow to control the occurrence of unauthorized voltage in the electrical network. These devices allow to determine, using voltage sensors installed at different points of network, the side from which the voltage is applied, or to determine, with help of current or power sensors, the change in the direction of the power flow and, based on where the voltage is applied or in which direction the power flow is directed, to determine the facts of unsanctioned voltage supply to the network, including, if considering networks of $0.4-10 \mathrm{kV}$, the facts of unsanctioned voltage supply to the network from $0.4 \mathrm{kV}$. Figure 1 shows a diagram of the $10 / 0.4 \mathrm{kV}$ transformer substation (TS) with reference points at which the voltage is measured and the direction of the power flow is determined to illustrate the method and techniques for detecting unauthorized voltage supplied from the $0.4 \mathrm{kV}$ side, as well as to prevent its reverse transformation. The peculiarity of the proposed method is that it allows to detect cases of reverse transformation without using measurements from the high side of the transformer. This is achieved by placing voltage and current sensors at the control points indicated in the figure. The method is described below.

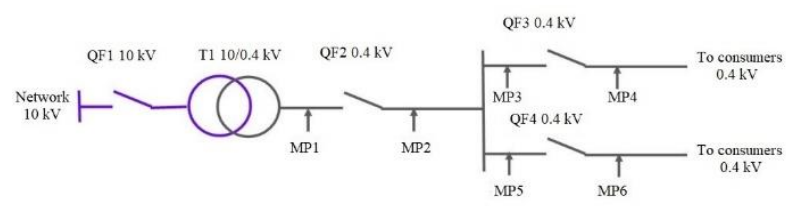

Fig. 1. 10/0. $4 \mathrm{kV}$ TS diagram with indication of control points where voltage is measured and the direction of power flow is determined to detect unauthorized voltage supplied from the $0.4 \mathrm{kV}$ side, as well as to prevent its reverse transformation. 
Accordimg to the figure : T1-power transformer 10/0.4 kV, QF - Switching device, CP - Control point.

Main signposts for the recognition of various situations in power grids are the sequences of changes in voltage and current at control points. Based on the analysis of these sequences, various authors have developed many solutions for monitoring the operating modes of power grids of different voltages [30,31]. Specific changes in current and voltage are also used in monitoring systems of power grids [4]. This concept allows to control the occurrence of unsanctioned voltage in the power grids. So, the sequence of changes in the voltage and the direction of the power flow at the control points indicated in Figure 1 in a situation where the voltage disappears from the $10 \mathrm{kV}$ side and then appears on $0.4 \mathrm{kV}$ side is shown in Figure 2.

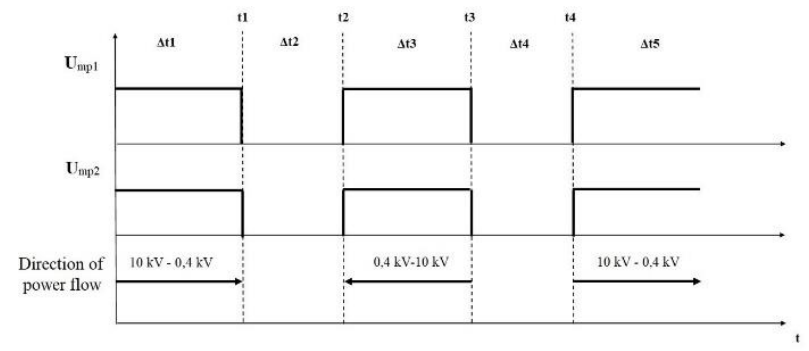

Fig. 2. Diagram of the voltage change and the direction of the power flow in the case of disconnection from the $10 \mathrm{kV}$ side and subsequent supply of voltage from the $0.4 \mathrm{kV}$ side without the use of reverse transformation blocking means.

The diagram shows the voltage change at the control points $\mathrm{KT} 1$ and $\mathrm{KT} 2$, that is, at the points relative to the switching device KA2 from the $10 \mathrm{kV}$ side and from the $0.4 \mathrm{kV}$ side. In principle, the voltage, in the case of a closed position of all switching devices, changes at all points equally. Analysis of the diagram shown in Figure 1 shows that when the voltage is switched off from the $10 \mathrm{kV}$ side and the voltage is subsequently applied from the $0.4 \mathrm{kV}$ side without using reverse transformation blocking means, the main difference between the voltage supply modes from the $10 \mathrm{kV}$ side and from the $0.4 \mathrm{kV}$ side is only a change in the direction of power flow. In the first case, the power flow is directed towards the 0.4 $\mathrm{kV}$ transmission line, which is due to its consumption by consumers connected to the $0.38(0.4) \mathrm{kV}$ transmission line. In the second case, the flow is directed towards 10 $\mathrm{kV}$, which is due to the idling of the $10 / 0.4 \mathrm{kV}$ transformer and the loads on the $10 \mathrm{kV}$ side, as well as the loads of $0.4 \mathrm{kV}$ connected above the reference point (for example, the load of measuring equipment). This sequence of changes in the direction of the power flow can be used as an information feature to determine the side from which the voltage is applied $(0.4 \mathrm{kV}$ or 10 $\mathrm{kV})$.

A number of methods of signaling and blocking from reverse transformation on the $10 / 0.4 \mathrm{kV}$ TS have been developed, including when an unsanctioned voltage appears in particular $0.4 \mathrm{kV}$ lines, and methods for twotransformer substations, where the implementation of control is complicated by the fact that it is possible for an sanctioned voltage to appear on the $0.4 \mathrm{kV}$ tires after disconnecting the $10 \mathrm{kV}$ side, since the $0.4 \mathrm{kV}$ voltage can be applied from the second section of the TS tires (Patents of the Russian Federation №№ 2710938, 2714495, 2713630, 2714669, 2739326, 2740002 and others).

Ensuring the possibility of monitoring the unsanctioned occurrence of voltage using the above methods requires disconnecting the switching device $\mathrm{KA} 2$, or devices KA3, KA4 (Figure 1), installed, accordingly, at the low voltage input and in the outgoing lines. A number of methods were implemented in the course of research and development work in the Branch of "MRSK Center -Voronezhenergo"), devices for implementing signaling and blocking reverse transformation at one - and two-transformer substations were conducted. [21,31].

\section{Results and discussion}

A number of methods of signaling and blocking against reverse transformation on the $10 / 0.4 \mathrm{kV}$ TS have been developed, including when an unauthorized voltage appears in specific $0.4 \mathrm{kV}$ lines and methods for twotransformer substations, where the implementation of control is complicated by the fact that it is possible for an authorized voltage to appear on the $0.4 \mathrm{kV}$ tires after disconnecting the $10 \mathrm{kV}$ side, since the $0.4 \mathrm{kV}$ voltage can be applied from the second section of the TS tires (Patents of the Russian Federation №№ 2710938, 2714495, 2713630, 2714669, 2739326, 2740002 and others). Ensuring the possibility of monitoring the unauthorized occurence of voltage using the above methods requires disconnecting the switching device QF2, or devices QF3, QF4 (Figure 1), installed, respectively, at the low voltage input and in the outgoing lines. Several methods were implemented in the course of research and development work in the Branch of IDGC of Center PJSC-Voronezhenergo, devices for implementing signaling and blocking reverse transformation at one - and two-transformer substations were made $[32,33]$.

Let's illustrate with the block diagram in Figure 3 the implementation of the method of blocking the reverse transformation on the $10 / 0.4 \mathrm{kV} \mathrm{TS}$, which involves disconnecting both the input switching device and the switching devices in the outgoing lines and is based on monitoring the voltage at different points of the network[34]. 


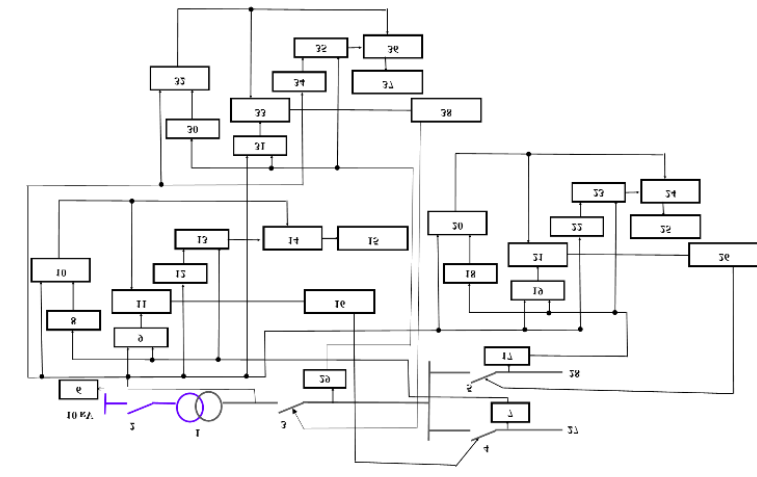

Fig. 3. Block diagram of the implementation of reverse transformation blocking method on the $10 / 0.4 \mathrm{kV}$ TS.

The block diagram contains the following elements: 1-power transformer; 2-input switching device on the high side of the transformer substation; 3-input switching device on the low side of the transformer substation; 4, 5-switching devices of low-voltage outgoing lines; 6, 7, 22, 29-voltage sensors; 8, 30, 34elements that implement the logical function NOT; 9, 12, 19, 31-elements that implement the logical function AND-NOT; 10, 13, 20, 23, 32, 35 - elements that implement a logical function AND; 11, 14, 21, 24, 36 storage elements; 15, 25, 37 - devices for transmitting data and displaying information on the spot; 16, 26, 38 devices for disconnecting the switching device; 27, 28outgoing low-voltage power lines. The scheme works as follows: voltage sensors $6,7,22,29$ monitor the voltage at the corresponding points of the network in which they are installed. In normal mode, at outputs 6, 7, 17 and 29, there are signals transmitted to the corresponding circuits of logic elements, the operation of which leads to missing output signals of the elements $9,10,13,20,23$, $19,31,32,35$, the circuit does not launch.

When the voltage at the input of the transformer substation (TS) disappears from the high voltage side and on the outgoing lines 27 and 28, as well as on the low voltage buses of the TS, the signals from the outputs of the sensors $6,7,17,29$ disappear, which leads to the occurrence of a signal at the outputs of elements 9, 19, 31. These signals are stored, respectively, by elements 11,21 and 33 and are fed to the inputs of the switching devices of switching devices 16, 26 and 38, which disable, accordingly, in this case, switching devices 4, 5, 3. Thus, the possibility of reverse transformation is blocked If the voltage is applied from the low side, then due to the disconnected position 4,5 and 3 , it cannot be applied to the power transformer 1 .

If the voltage appears on the side of the outgoing line 27 and does not appear on the high side of the power transformer, then a signal from the sensor 7 will also appear, which will be applied to one of the inputs of the element 13 and there will be no signal from the sensor 6 . Therefore, a signal from the element 12 will be present at the second input of the element 13. In this case, from the output of element 13, the signal will be fed to the input of element 14, stored by it and fed to the data transmission and information display device 15. An alarm about unsanctioned voltage supply to the line 27 will be provided by transmitting information to the network dispatcher and displaying information on the spot (by sound, light signal, or (and) displayed on the monitor, displayed in another way).

The circuit returns to default mode when a voltage appears on the side of the power transformer and there is no voltage on the side of the outgoing line 27 . In this case, there is a signal from the output of element 6 and there is no signal from output 7 , therefore, signals will be sent to both inputs of element 10, a signal will appear at its output and reset elements 11 and 14, thus returning the circuit to its original state. Likewise, the occurrence of unsanctioned voltage in the outgoing line 28 and the low-voltage buses of the TS is monitored. The alarm is provided by the operation of the corresponding logic elements.

A device for signaling and blocking the reverse transformation is developed, which implements the method illustrated in Figure 3. The type of the device is shown in Figure 4. The LED indicators FROM indicate the fact of reverse transformation, and $\mathrm{HH}$-the appearance of unauthorized voltage. also, the device body contains connectors for connecting switching devices, connecting the device to the substation's tele mechanics, and connecting other circuits. Current transformers TT1-TT3 allow you to control the current flowing through the measuring current circuits and, due to this, to identify the facts of reverse transformation. The LED display matrix provides an indication of the position of the switching devices, as well as an indication of the presence of voltage on all connected circuits.

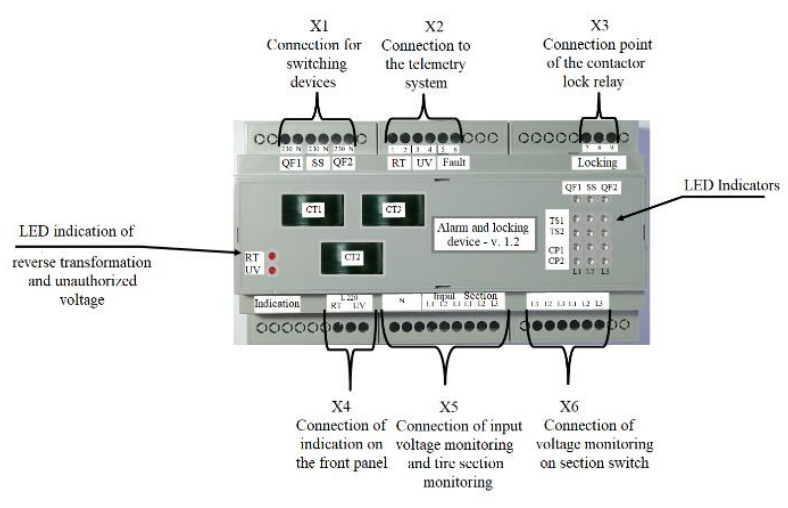

Fig. 4. View of the reverse transformation alarm and blocking device.

In addition to signaling and blocking from reverse transformation, the device performs the tasks of monitoring the operating modes of the substation and transmitting information about the operation of switching devices at the substation, the presence of voltage at control points, and so on to the network dispatcher. according to the protocols IEC-104, IEC$61850[35,36]$.

\section{Conclusions}

1. Monitoring the parameters of the operating modes of power grids makes it possible to increase the observability of power grids and implement ways to 
improve the reliability of power supply to consumers, the quality of electricity supplied to them.

2 . One of the upcoming challenges of monitoring the parameters of the operating modes of electric networks is to control the occurrence of unsanctioned voltage in the network, as a situation that can lead to people falling under the influence of voltage. Also, the detection of unsanctioned voltage allows to block the possibility of reverse transformation of low voltage to medium voltage at transformer substations, which additionally increases the safety of operation of power grids.

3. Application of the studied method of blocking the reverse transformation on the $10 / 0.4 \mathrm{kV} \mathrm{TS}$, which involves disconnecting both the input switching device and the switching devices in the outgoing lines and is based on monitoring the voltage at different points of the network, prevents the possibility of reverse transformation and unsanctioned supply of voltage to the medium-voltage network, as well as provides signaling and informing the staff of the power grid organization about unsanctioned supply of voltage to specific lowvoltage power lines departing from the transformer substation and to the low-voltage buses of the transformer substation.

\section{References}

1. Vinogradov A.V. Development of principles for managing the configuration of rural power grids and technical means for their implementation: dissertation for the degree of Doctor of Technical Sciences in the specialty 05.20.02-Electrical technologies and electrical equipment in agriculture/Vinogradov Alexander Vladimirovich; FGBNU FNAC VIM. Moscow. 527. (2021)

2. Kirkman R. Development in substation automation systems. - $\quad$ Available at: http://www.ee.nsysu.edu.tw/isap2007CD/papers/f00 83.pdf

3. Pereda R. et al. Substation automation experiences based on the IEC 61850 GOOSE messages //23rd International Conference on Electricity Distribution. -15-18. (2015). Available at: http://cired.net/publications/cired2015/papers/CIRE D2015_0596_final.pdf

4. Vinogradov, A., Bolshev, V., Vinogradova, A., Kudinova, T., Borodin, M., Selesneva, A., \& Sorokin, N. A System for Monitoring the Number and Duration of Power Outages and Power Quality in $0.38 \mathrm{kV}$ Electrical Networks //International Conference on Intelligent Computing \& Optimization. - Springer, Cham, 1-10. (2019).

5. Powering. Reliable. Future. Yesterday, today and tomorrow. RWE Annual Report 2017. Essen, Germany: RWE Aktiengesellschaft. (2017).

6. Innovation Report/2014-2015. IBERDROLA 2014 2015 Innovation Report (2015). - Available at: https://www.iberdrola.com/wcorp/gc/prod/en_US/so stenibilidad/docs/informe_innovacion_2014_2015.p df
7. Bukreev A.V., Vinogradov A.V., Semenov A.V., Kuzmin A.V. The use of sensors for parameters of operating modes of electric networks for analyzing the reliability of power supply to consumers and the quality of electricity supplied to them / A.V. Bukreev, A.V. Vinogradov, A.V. Semenov, A.V. Kuzmin / Agrotechnika i energoobespechenie. - №4 (29). - Pp. 15-24. (2020)

8. Dovgun V., Temerbaev S., Chernyshov M., Novikov V., Boyarskaya N., Gracheva E., Distributed power quality conditioning system for three-phase four-wire low voltage networks/ Energies, Volume 13, Issue 18. art. no. 4915, DOI: 10.3390/en13184915. (2020).

9. Momoh J. A. Smart grid design for efficient and flexible power networks operation and control // Power Systems Conference and Exposition, PSCE '09. P. 1-8. (2009).

10. Goulden M., Bedwell B., Rennick-Egglestone S., Rodden T, Spence A. Smart grids, smart users? The role of the user in demand side management Energy // Energy Research \& Social Science, Vol. 2. P. 219. (2014)

11. Yasin Kabalci. A survey on smart metering and smart grid communication // Renewable and Sustainable Energy Reviews. Vol. 57. P. 302-318. (2016)

12. Mohassel R. R., Fung A., Mohammadi F., Raahemifar K. A survey on Advanced Metering Infrastructure // Electrical Power and Energy Systems. Vol. 63. P. 473-484. (2014)

13. Advanced metering infrastructure (AMI) // Electric Power Research Institute (EPRI). (2007).

14. Faruqui, A., Arritt, K., Sergici, S. The impact of advanced metering infrastructure on energy conservation: A case study of two utilities // The Electricity Journal. Vol. 30. P. 56-63. (2017).

15. Bolshev V. E., Vinogradov A.V. Review of foreign sources on the infrastructure of smart meters/ / Bulletin of the South Ural State University. Series "Energetika". - Vol. 18. No. 3. - p. 5-13. (2018).

16. Identification of power line sections with increased electricity losses using mobile portable timerselectric meters / Vinogradov A.V., Bukreev A.V., Vinogradova A.V., Bolshev V. E./ / Electrotechnologies and electrical equipment in the agro-industrial complex. No. 3 (40). pp. 31-36. DOI: 10.22314/2658-4859-2020-67-3-31-36 (2020).

17. Bolshev, V. E. Development of technical means for monitoring disconnections and voltage deviations at the inputs of rural consumers: dissertation for the scientific degree of Candidate of technical Sciences: 05.20.02 / Vadim E. Bolshev. - 224p. Moscow, (2020).

18. Golikov I. O. Adaptive automatic voltage regulation in rural power grids of $0.38 \mathrm{kV}$ : dissertation for the scientific degree of Candidate of Technical Sciences: 05.20.02 / Golikov Igor Olegovich. 200 p.Orel, (2016). 
19. Borodin M. V. Improving the efficiency of the functioning of power supply systems by monitoring the quality of electricity. Monography / Borodin M. V., Vinogradov A.V.-Orel: FGBOU VPO Orel GAU, 160 p., ISBN 978-5-93382-230-1 (2014).

20. A.V. Vinogradov, V.E. Bolshev, A.V. Vinogradova, A.A. Lansberg, M.O. Ward and N.K. Miftakhova Method of accounting the dynamics of technological connections when forming a list of objects for the reconstruction and construction of power grids 01030. E3S Web of Conferences, Volume 178 (2020) High Speed Turbomachines and Electrical Drives Conference 2020 (HSTED-2020), Prague, Czech Republic, May 14-15, 2020. Published online: $09 \quad$ July $2020 . \quad$ DOI: https://doi.org/10.1051/e3sconf/202017801030

21. Vinogradov A.V., Bolshev V. E., Revkov A. A. Sensor for monitoring the reliability of power supply and quality of electricity / / Energo - i resursosberezhenie-XXI: materials of the XVIII International scientific and practical conference (December 8-10, 2020, Orel) / edited by Dr. Kachanov A. N., Dr. Stepanov Yu.S. - Orel: OSU named after I. S. Turgenev, 292 p. - p. 234-238 (2020).

22. Regulation on technical policy in the distribution grid complex. Addendum to Decree No. 228 of PJSC Centre and North Caucasus, dated 14.11.2006 - Available at: http://programma.xpdf.ru/16tehnicheskie/220204-1-polozhenietehnicheskoy-politike-raspredelitelnomelektrosetevom-komplekse-moskva-nastoyascheepolozhenie-tehnicheskoy-pol.php

23. Regulation of PJSC "Rosseti" on the unified technical policy in the electric grid complex. Moscow: PJSC "Rosseti", 196 p. (2013).

24. The Regulation of PJSC "Rosseti» «the Unified Technical Policy in the Electric Grid Complex" "was approved by the Council of Directors of PJSC "Rosseti" (Minutes No. 252 of 22.02.2017) Available at: file://C:/Users/user/Downloads/\%D0\%A $\%$ D0\%A 2\%D0\%9E\%2034.01-5.1-008-2018.pdf

25. Vinogradov A.V., Vinogradova A.V., Skiteva I. D., Panfilov A. A. Comparative analysis of the reliability of power supply in the districts of power grids / / Innovations in agriculture. - №3(28). p. 3946. (2018).

26. Decree of the Government of the Russian Federation No. 861 of December 27, 2004 "On Approval of the Rules for Non-Discriminatory Access to Services for the Transmission of Electric Energy and the Provision of these services, the Rules for nondiscriminatory access to services for operational Dispatch Management in the electric power industry and the provision of these services, the rules for non-discriminatory access to the services of the administrator of the wholesale market trading system and the provision of these services, and the rules for technological connection of power receiving devices of electric energy consumers, electric energy production facilities, as well as electric grid facilities belonging to grid organizations and other persons to power grids ". Available at: http://www.consultant.ru/cons/cgi/online.cgi?req=do c\&base $=$ LAW\&n $=349429 \&$ fld $=134 \&$ dst $=10000000$ $01,0 \& \mathrm{rnd}=0.01637230187499794 \# 0806868478485$ 0308

27. Analysis of accidents at power facilities controlled by Rostechnadzor authorities for 2017. // szap.gosnadzor.ru : Federal Service for Environmental, Technological and Nuclear Supervision (Rostechnadzor) (2020).

28. Federal Law No. 471-FZ 27.12.2019 "On Changes to the Federal Law" On Electric Power Industry " regarding the Development of microgeneration»

29. Resolution of the Government of the Russian Federation of March 5, 2021 N 328 " On changes to certain acts of the Government of the Russian Federation on the promotion of the use of renewable energy sources in the wholesale market of electric energy and capacity»

30. Belikov, R. P. The use of control and switching devices for remote detection and elimination of damage in relation to branched power grids of 6 (10) kV / R. P. Belikov, I. N. Fomin / / Agrotechnika i energoobespechenie. - № 4 (17). 77-86. (2017).

31. Fomin, I. N. Control of disconnection of highvoltage circuit breakers in a partitioned power transmission line / I. N. Fomin, R. P. Belikov // Vesti vyshnykh uchebnykh zavedeniy Chernozemya. № 2 (56). 48-59. (2019).

32. Vinogradov A.V., A. A. Panfilov, A. S. Bredikhin, S. A. Kanyus, M. V. Borodin, A.V. Vinogradova, A.V. Bukreev, V. E. Bolshev, A. I. Psarev, Yu. B. Ryzhenkov, A. A. Lansberg, Variants of execution of signaling devices and blocking from reverse transformation at transformer substations of 10/0. 4 $\mathrm{kV} /$ / Glavny energetik. No. 10. 5-14 (2020).

33. Vinogradov A.V., Vinogradova A.V., Bolshev V. E., Bukreev A.V., Panfilov A. A., Borodin M. V., Bredikhin A. S., Kanyus S. A. Method and device for preventing reverse transformation at $10 / 0.4 \mathrm{kV}$ transformer substations with unsanctioned supply of voltage to the $0.4 \mathrm{kV}$ network/ A.V. Vinogradov, A.V. Vinogradova, V. E. Bolshev, A.V. Bukreev, A. A. Panfilov, M. V. Borodin, A. S. Bredikhin, S. A.// Industrial power engineering. No. 7. pp. 56-62 (2020).

34. Patent No. 2710938 Russian Federation, IPC N02J 9/06, N 02 J 13/00. A method for blocking reverse transformation by disconnecting switching devices in the low-voltage power lines departing from the transformer substation and the input switching device on the low side of the transformer substation and signaling and informing the personnel of the power grid organization in case of unsanctioned voltage supply to the low-voltage power lines departing from the transformer substation from 
consumers or to the low-voltage buses of the transformer substation /Vinogradov A.V., Vinogradova A.V., Panfilov A. A., Bolshev V. E.; applicant and patent holder of FGBNU FNAC VIM. - Application 2019133614; declared 23.10.2019; Publ. 14.01.2020 Byul. no. 2.

35. GOST R IEC 60870-5-104-2004. National Standard of the Russian Federation "Telemechanics devices and systems" Part 5. Transmission protocols. Section 104. Network access for GOST R IEC 8705-101 using standard transport profiles. Available at: http://docs.cntd.ru/document/gost-r-mek-60870-5104-2004.

36. GOST R IEC 61850-5-2011 National Standard of the Russian Federation. Networks and communication systems at substations. Part 5 . Communication requirements for functions and device models. Electronic resource. Title from the screen. Available at: http://docs.cntd.ru/document/1200093460. 